\title{
Oncofly: A CURE for Cancer
}

\author{
Floyd A. Reed and H. Gert de Couet
}

School of Life Sciences, The University of Hawai'i at Mānoa, Honolulu HI 96822

\begin{abstract}
Course-based Undergraduate Research Experiences (CURE’s) are emerging as a means to engage large numbers of undergraduate students in meaningful inquiry-based research activities. We describe here a simple laboratory exercise as part of an undergraduate genetics course that illustrates the contributions of oncogenes and tumor suppressors to the formation of neoplasms in an invertebrate model system. In addition, students were challenged to investigate whether flies reared on a diet containing a variety of additives display a higher number of invasive tumors in the larval abdomen.

The goal of the exercise was to (i) familiarize students with the multigenic origin of the cancer phenotype, to (ii) introduce some of the fundamental molecular cancer hallmarks, and to (iii) highlight

15 the significance of invertebrate model systems in biomedical research. Furthermore, (iv) students learn to execute a molecular test for transgenic produce and (v) apply statistical tools to test a simple hypothesis.
\end{abstract}

We evaluated student learning and changes in opinions and attitudes relating to environmental versus genetic causes of cancer and several common misconceptions using a questionnaire before and after 20 completing the exercise.

Overall, significant improvements in the rate of factually correct responses and reductions in uncertainty were demonstrated. Although resistance to change was apparent in regard to identifying some risk factors, there was clear learning and understanding of the core concepts of carcinogenesis 
and the utility of basic research with model organisms.

\section{Introduction}

We teach that science is based upon replicable research that builds both a descriptive and predictive mechanistic model of the world around us, should embrace critical thinking, and not be dogmatic. Ideally students would be directly exposed to self guided research questions; however, in practice students are often given lists of facts to memorize and participate in "canned” laboratory exercises where the expected outcome is already known. This falls far short of teaching how science is actually done and does not set the stage to foster creativity, critical thinking, model building, and hypothesis testing (Handelsman et al. 2004). Inquiry-based research opportunities for undergraduates exist for a minority of students. This practice is partly driven by the objective to create an educational

35 pipeline that leads a fraction of undergraduate students to graduate school or a medical career. The benefits of hands-on, inquiry-based research experiences for the training of a future biomedical work force are undisputed (e.g., Russell et al., 2007). Limiting this to advanced special courses or participation in a research laboratory selects for a cadre of students who focus on a specific educational trajectory and a major early in their coursework and excludes the majority of undergraduates. It is recognized that most institutions lack the resources to provide these opportunities for a sizable portion of undergraduate majors (Wood 2003; Desai et al. 2008; Harrison et al. 2011, cited in Auchincloss et al. 2014; Brownell et al. 2015). Course-based Undergraduate Research Experiences (CURE’s) are designed to address this disconnect and give a broader range of students an opportunity to conduct research in the classroom (Wei and Woodin 2011; Auchincloss et al. 2014; Jordan et al. 2014; Brownell 45 et al. 2015). CURE's have been shown to have a wide range of positive effects such as increasing graduation rates and improving the interpretation of data (Goldey et al. 2012; Brownell et al. 2015; 
Rodenbusch et al. 2016).

Cancer biology is typically a specialty topic only offered to graduate and medical students because of subject complexity and relevance to therapeutic intervention and treatment. However, cancer biology can be instrumental in teaching fundamental concepts of cell-and molecular biology. Practically all aspects of cellular function—metabolism, cellular signaling, epigenetics, DNA replication and repair-are impacted by cancer. Here we argue that cancer biology can be utilized as a powerful undergraduate teaching opportunity.

In teaching biology, topics that are relevant to the students' lives outside of academia help

55 capture interest and build upon a preexisting conceptual framework. Essentially everyone has been impacted by cancer on some level at some point in their lives (ACS 2014) making the topic an immensely personal one. Student surveys conducted early in a genetics course (from 2011 to 2017, BIOL 375, Dept. of Biology, UH Mānoa) consistently found high interest in learning more about 'genetically modified organisms' and 'cancer genetics'. In addition, there is widespread persistent

60 misinformation about the causes and treatments of cancer (Shahab et al. 2018). People care about cancer and this interest can be used to effectively communicate fundamental principles of genetics and cell biology as well as teach sophisticated genetic tools, the value of model organisms and basic research, address common misconceptions and controversial issues, and even place cancer and genetics into both a social and evolutionary context. Here we present a teaching laboratory module designed for life science undergraduates which uses a range of state-of-the-art genetic tools to generate benign tumors in the Drosophila melanogaster model. Drosophila melanogaster also simply referred to as Drosophila, has been a cancer model for over a century (Villegas 2019) and Drosophila is a tractable system in CURE settings (Chen et al. 2005). The student exercise described here is based on a study by Pagliarini and Xu (2003), which 70 used Drosophila to generate tumors in the optic lobes of the fly by "two hit" over-expression of an 
oncogenic variant of the Ras gene in a background of cells deprived of the scrib tumor suppressor gene product by a loss-of-heterozygosity. Using the technique of mosaic analysis with a repressible cell marker (MARCM), these clones express a green fluorescent protein and tumors arising from these clones are easily visualized in vivo.

A critical point in development of cancer is the transition from a benign to a malignant tumor.

This occurs when the tumor gains the ability to metastasize. Some of these 'engineered' Drosophila neoplasms seed secondary tumors in the thorax and abdomen of fly larvae-an insect analogue of metastasis. (The question of the validity of this term in relation to the satellite tumors found in the Drosophila model is discussed later.) This cellular behavior can be used to screen for substances that either promote or suppress this process (Willoughby et al. 2013). The effects of food additives and treatments, which can be discussed and selected collectively by the students, upon the rates of metastases are quantified in blind experiments. The data are shared with the class, statistically tested in aggregate, and reported by the students. The guided selection of treatments can follow current events regarding cancer biology. The equipment needed fits within most college laboratory budgets and can

85 also be used in a range of other biology teaching projects. The experiment consists of a single cross and can easily be conducted by the students in a few calendar weeks. Because of the complexity of the strains used and the underlying mechanisms the exercise can easily be adapted to different educational levels and goals.

In the initial version of this experiment we combined a CURE centered on analyzing local 90 produce for genetic modification with the introduction of principles of carcinogenesis in the expectation that it would facilitate discussions among the students about the scientific basis of claims regarding carcinogenicity of GM foods (Séralini et al. 2012; Casassus 2013; Grunewald and Bury 2013; Hammond et al. 2013; Hayes 2013; Panchin 2013; Romeis et al. 2013; Goldstein 2014; Wallace 2014). 
epidemic of Papaya Ringspot Virus devastated the main production areas on the island of Hawai`i. A transgenic variant of papaya expressing a fragment of the viral capsid protein gene proved to be resistant against the disease and rescued the industry (Gonsalves 1998; Ferreria et al. 2002; Kallis 2013). Today, the transgenic "Rainbow" cultivar represents the majority of Hawai 'i's papaya crop. The genome of the transgenic variant was sequenced in 2008 (Ming et al. 2008), which played a major role in broadening the export market beyond the North American continent by defusing concerns about the generation of immunogenic proteins as a result of inserting an open reading frame into the plant genome.

The initial GMO-focused CURE was broadened from genetically modified papaya to testing

105 additional food additives, from health drinks to styrofoam, over the following semesters. This underscores the teaching modules' flexibility to address a wide range of questions. We observed a surprising result; butyrate_-generally considered to be protective against cancer in humans_raised the apparent rate of insect metastases. There were significant increases in students' understanding of cancer and cancer related topics; however, students' responses regarding risk factors and causes of cancer,

110 although overall significantly improved according to the prevalent current scientific literature, remained resistant to change among a large fraction for topics such as GM food, power lines, and cell phone use. Students also appeared to suffer from lower retention of quantitative rather than qualitative facts, which is an area that could benefit from further exploration. Finally, the utility of model organisms to study medical phenomena such as cancer was widely appreciated with a $99.8 \%$ positive

115 response after completing the module.

\section{Results and Discussion}




\section{Experimental Results}

Six food additives were double-blind tested over three semesters of teaching the module. Students and controls until after scoring. This type of data can readily be analyzed in a $2 \times 2 \chi^{2}$ contingency table of independence - the students should have some familiarity with the $\chi^{2}$ test as it is often used in genetics classrooms for data analysis. No significant effect was detected on the rate of metastases with four substances: GMO versus non-GMO papaya (Carica papaya), commercial noni juice (Morinda citrifolia), multivitamin dietary supplements (“Telovites”), and polystyrene used in food packaging. Two substances resulted in a significant (using a standard $P<0.05$ cutoff) elevation of the rate of metastases: a glyphosate-based herbicide (Roundup) and butyrate (see Table 1).

\begin{tabular}{|l|l|l|l|l|}
\hline Additive & Relative change & Sample Size & $\chi^{2}$ value & $P$ value \\
\hline Noni juice & - & 322 & 1.49 & 0.22 \\
\hline Multivitamin & - & 275 & 1.68 & 0.19 \\
\hline GMO Papaya & - & 481 & 2.94 & 0.086 \\
\hline Polystyrene & - & 372 & 3.406 & 0.065 \\
\hline Roundup & $4.9 \%$ & 360 & 3.99 & $0.046 *$ \\
\hline Butyrate & $10.5 \%$ & 418 & 13.2 & $2.8 \times 10^{-4 * *}$ \\
\hline Temperature & $28.3 \%$ & 1168 & 124.75 & $1.2 \times 10^{-6 * *}$ \\
\hline
\end{tabular}

Table 1. Summarized results of treatments and insect metastases ordered by statistical significance. Relative change in the rates of metastases are given for treatments with a $P$-value less than 0.05 . All $\chi^{2}$ tests had one degree of freedom. The GMO papaya was compared to a control with the same amount of non-GMO papaya added. Temperature was compared by rearing Drosophila at $19 \mathrm{C}$ versus $23 \mathrm{C}$. All other tests were done without the food additive added to the control food. * indicates results that are significant with a $\mathrm{p}<0.05 . * *$ indicates results that are significant after a multiple testing correction over all experiments. 
There was also a significant effect of temperature. The GAL4/UAS system used in this cross is temperature sensitive (Duffy 2002). When crosses are conducted at $23 \mathrm{C}$ versus $19 \mathrm{C}$ there is a significant elevation of mestatases. This underscores the need to run a randomly placed control in parallel during the course of each new experiment in order to account for environmental fluctuations.

It is also appropriate to point out to the students - especially when presenting the results from past semesters - the issues of multiple testing and replication. It is expected that by chance one out of twenty tests will have a $P$-value of less than 0.05 if the test used is appropriate and there is no actual mechanistic effect of the treatment (a type I error). A Bonferroni correction (e.g., Cabin and Mitchell

145 2000), while conservative, is the easiest to initially understand and use. It keeps the total false positive rate at $5 \%$ by multiplying each $P$-value by the total number of tests done. In this example only butyrate and temperature have significant effects after the correction. Finally, none of these experiments have been replicated outside of a single semester classroom. Replication of an earlier experiment, especially given the potential sensitivity to environmental conditions, and subsequent meta-analysis should also

150 be proposed to the students as an important choice for testing.

Many of the substances tested fall squarely within developing results and debate-the reason for selection—which we argue enhances students' interest in analyzing and communicating the results. The carcinogenic potential of glyphosate is of particular current focus because of the controversy surrounding recent court cases (e.g., Charles 2019, Peterson 2019) and the results found by the students

155 illustrate the degrees of uncertainty inherent in scientific research, which can increase interest in science (Retzbach and Maier 2015). Claims about the health effects of noni (Morinda citrifolia) have also been debated (e.g., Brown 2012; Schulz 2014) and there are persistent statements about concerns regarding GMO food and cancer (e.g., Barrell 2019) as well as plastics, including styrene and polystyrene/styrofoam (e.g., Fox 2019; Christensen et al. 2018; with broader concerns about food 160 containers that can be tested in the future, e.g., Soto and Sonnenschein 2010; Liao and Kannan 2013). 
The multivitamin was chosen to be tested because it claims on its website that "TeloVite, [is] the first telomere lengthening multivitamin” and that it contains antioxidants

(https://www.westmartinlongevity.com/products/telovite/). Concerns can be found about possible negative effects of multivitamins and food supplements in general (e.g., Anonymous 2018; Chen et al.

165 2019), antioxidants and metastasis (e.g., Piskounova et al. 2015), and the relationship between telomere length and replicative potential of cancer cells is well documented (e.g., Blasco 2005; Williet et al. 2010). Butyrate is thought to be protective against the formation of some human cancers and combines current interests in understanding both microbiotic and epigenetic effects (Donohoe et al. 2012; Bultman 2017).

\section{Student Results}

Students were given identical questionnaires before starting the “oncofly” module and after its completion (Supplementary material 1). Students were instructed to give their candid individual response to the questions, omit their names or identifying information, and that they recieved full credit

175 for turning in a completed form regardless of responses. We were also interested in the effects of the laboratory project on their general knowledge of cancer rather than teaching them how to answer a limited set of specific questions. We were intentionally passive in presenting this information. The answers are contained in a handout (Supplementary material 2) and assigned reading materials, and aspects are touched upon both in lab presentations and an associated classroom lecture. However, students were not prompted to memorize the answers to these specific questions.

One part of the questionnaire asked students to rate statements on a scale from false (1) to uncertain (3) to true (5). The responses are summarized in Tables 2 and 3. 


\begin{tabular}{|l|l|}
\hline Keyword & Question \\
\hline Sharks & Sharks and insects do not get cancer. \\
\hline Artificial & Cancer only results from exposure to artificial substances. \\
\hline Organic & Cancer can be avoided by only eating organic food. \\
\hline Environment & Cancer only results from exposure to toxins or radiation in the environment. \\
\hline GMOs & GMO food is known to cause cancer. \\
\hline Cell phones & Cell phones cause cancer. \\
\hline Power lines & Power lines cause cancer. \\
\hline
\end{tabular}

185 Table 2. The keyword is only used here to guide comparisons between tables 2 and 3. It did not appear on the student questionnaire.

\begin{tabular}{|l|c|c|c|c|c|c|c|c|}
\hline Keyword & Pre-n & Post-n & Pre- & Post- & Correct P- & Pre- & Post- & Uncertain \\
& & & correct & correct & value (1) & uncertain & uncertain & P-value (2) \\
\hline Sharks & 578 & 575 & $61.2 \%$ & $78.6 \%$ & $2.2 \times 10^{-16}$ & $20.2 \%$ & $7.30 \%$ & $1.9 \times 10^{-10}$ \\
\hline Artificial & 422 & 420 & $93.4 \%$ & $97.1 \%$ & $2.0 \times 10^{-7}$ & $4.50 \%$ & $1.90 \%$ & 0.032 \\
\hline Organic & 578 & 576 & $91.2 \%$ & $91.7 \%$ & 0.033 & $5.36 \%$ & $5.38 \%$ & 0.989 \\
\hline Environment & 417 & 420 & $89.2 \%$ & $89.5 \%$ & $5.3 \times 10^{-3}$ & $5.04 \%$ & $4.29 \%$ & 0.607 \\
\hline GMOs & 578 & 576 & $52.1 \%$ & $64.6 \%$ & $2.2 \times 10^{-5}$ & $33.6 \%$ & $24.1 \%$ & $4.1 \times 10^{-4}$ \\
\hline Cell phones & 595 & 590 & $35.0 \%$ & $58.0 \%$ & $2.2 \times 10^{-16}$ & $31.8 \%$ & $24.4 \%$ & $4.8 \times 10^{-3}$ \\
\hline Power lines & 591 & 594 & $45.7 \%$ & $64.6 \%$ & $6.7 \times 10^{-16}$ & $39.4 \%$ & $26.1 \%$ & $1.0 \times 10^{-6}$ \\
\hline
\end{tabular}

Table 3. Statistical summary of the student questionnaire. Pre and Post refer to completing the

190 questionnaire before and after the module. $\mathrm{n}$ denotes number of students. The sample sizes can vary because of differences in student attendance, and some responses were incomplete. The percent with correct answers are given first and the proportion of uncertain responses are given next. $1 . P$-value from a Wilcoxon rank sum test. 2. $P$-value from a two-proportion z-test. 
195 The rate of correct, according to the current prevalent scientific literature, volunteered answers significantly improved for every question asked after participating in the oncofly project. Uncertainty of the correct answer declined significantly for the majority of questions asked and in no case increased significantly. For example, the proportion of students disagreeing with "GMO food is known to cause cancer” increased from $52.1 \%$ to $64.6 \%$ and uncertainty regarding the answer to this question decreased from $33.6 \%$ to $24.1 \%$. A summary of these results are plotted in figure 1 .

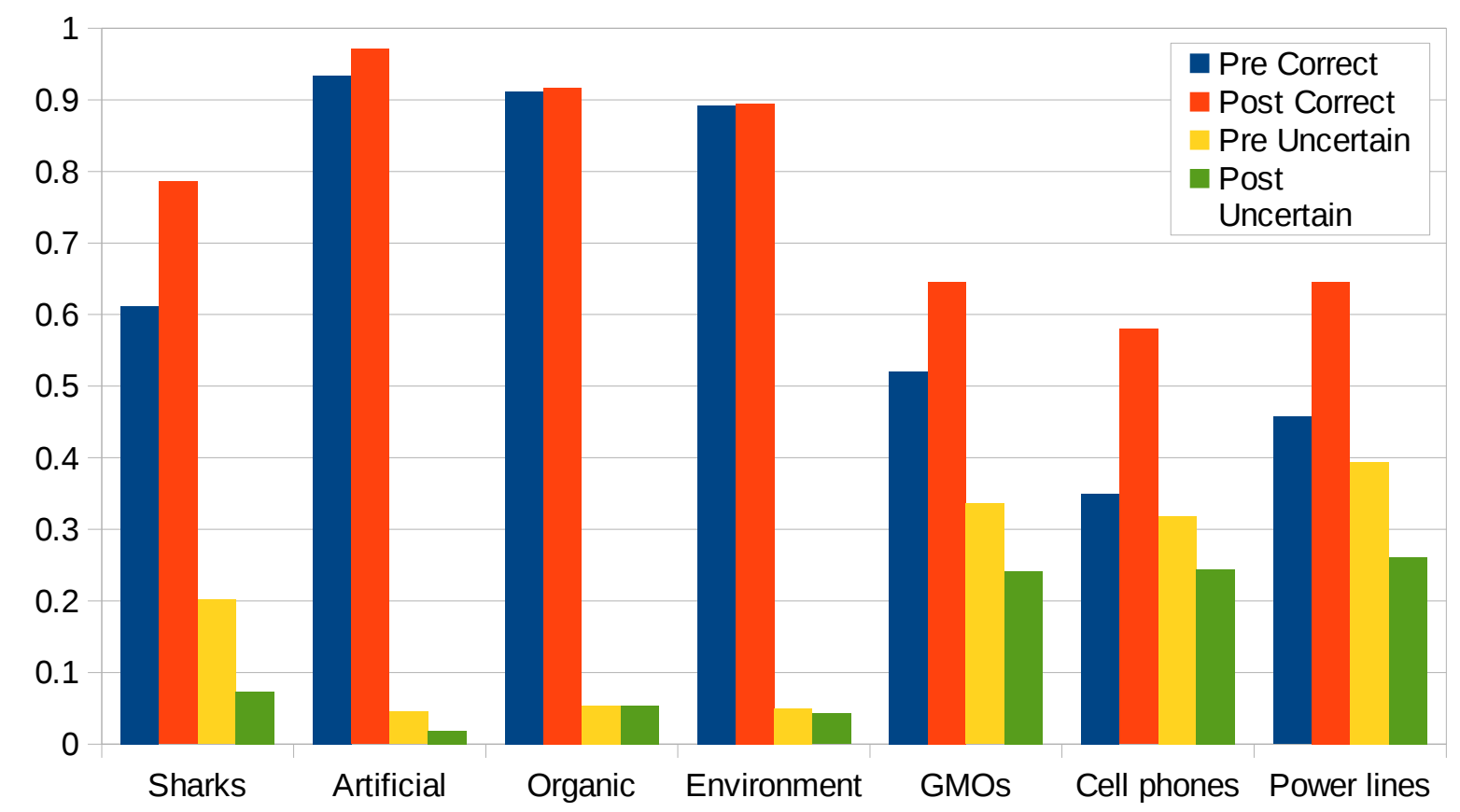

Figure 1. Plot of the results of correct and uncertain responses before and after the experiment. Data is detailed in Table 1. 
information.

\begin{tabular}{|l|l|}
\hline Keyword & Question \\
\hline Carcinogen & Can you name a known carcinogen that we are regularly exposed to? \\
\hline Gene types & What are the two types (categories) of genes that play a role in cancer? \\
\hline Cause & Do you know the leading cause of cancer in the US? \\
\hline Gene name & Can you name a cancer gene? \\
\hline Natural & Do you know any natural carcinogens? \\
\hline
\end{tabular}

Table 4. The keyword is only used here to guide comparisons between tables. It did not appear on the student questionnaire.

\begin{tabular}{|l|l|l|l|l|l|l|l|l|}
\hline Keyword & Pre-n & Post-n & $\begin{array}{c}\text { Pre- } \\
\text { correct }\end{array}$ & $\begin{array}{c}\text { Post- } \\
\text { correct }\end{array}$ & $\begin{array}{c}\text { Correct P- } \\
\text { value }\end{array}$ & $\begin{array}{c}\text { Pre- } \\
\text { uncertain }\end{array}$ & $\begin{array}{c}\text { Post- } \\
\text { uncertain }\end{array}$ & $\begin{array}{c}\text { Uncertain } \\
\text { P-value }\end{array}$ \\
\hline Carcinogen & 600 & 598 & $42.3 \%$ & $54.2 \%$ & $4.1 \times 10^{-5}$ & $33.8 \%$ & $21.7 \%$ & $3.0 \times 10^{-6}$ \\
\hline Gene types & 601 & 600 & $4.66 \%$ & $49.5 \%$ & $2.2 \times 10^{-16}$ & $65.2 \%$ & $14.2 \%$ & $2.2 \times 10^{-16}$ \\
\hline Cause & 600 & 600 & $37.7 \%$ & $65.5 \%$ & $2.2 \times 10^{-16}$ & $28.3 \%$ & $10.7 \%$ & $1.1 \times 10^{-14}$ \\
\hline Gene name & 600 & 597 & $20.7 \%$ & $64.2 \%$ & $2.2 \times 10^{-16}$ & $63.5 \%$ & $12.1 \%$ & $2.2 \times 10^{-16}$ \\
\hline Natural & 600 & 601 & $41.0 \%$ & $56.7 \%$ & $4.9 \times 10^{-8}$ & $47.7 \%$ & $26.8 \%$ & $7.2 \times 10^{-14}$ \\
\hline
\end{tabular}

Table 5. Uncertain answers (no or equivalent) were included with incorrect answers in quantifying and testing the proportion correct with a two-proportion z-test. The proportion of uncertain responses out of the total were also tested with a two-proportion z-test. 


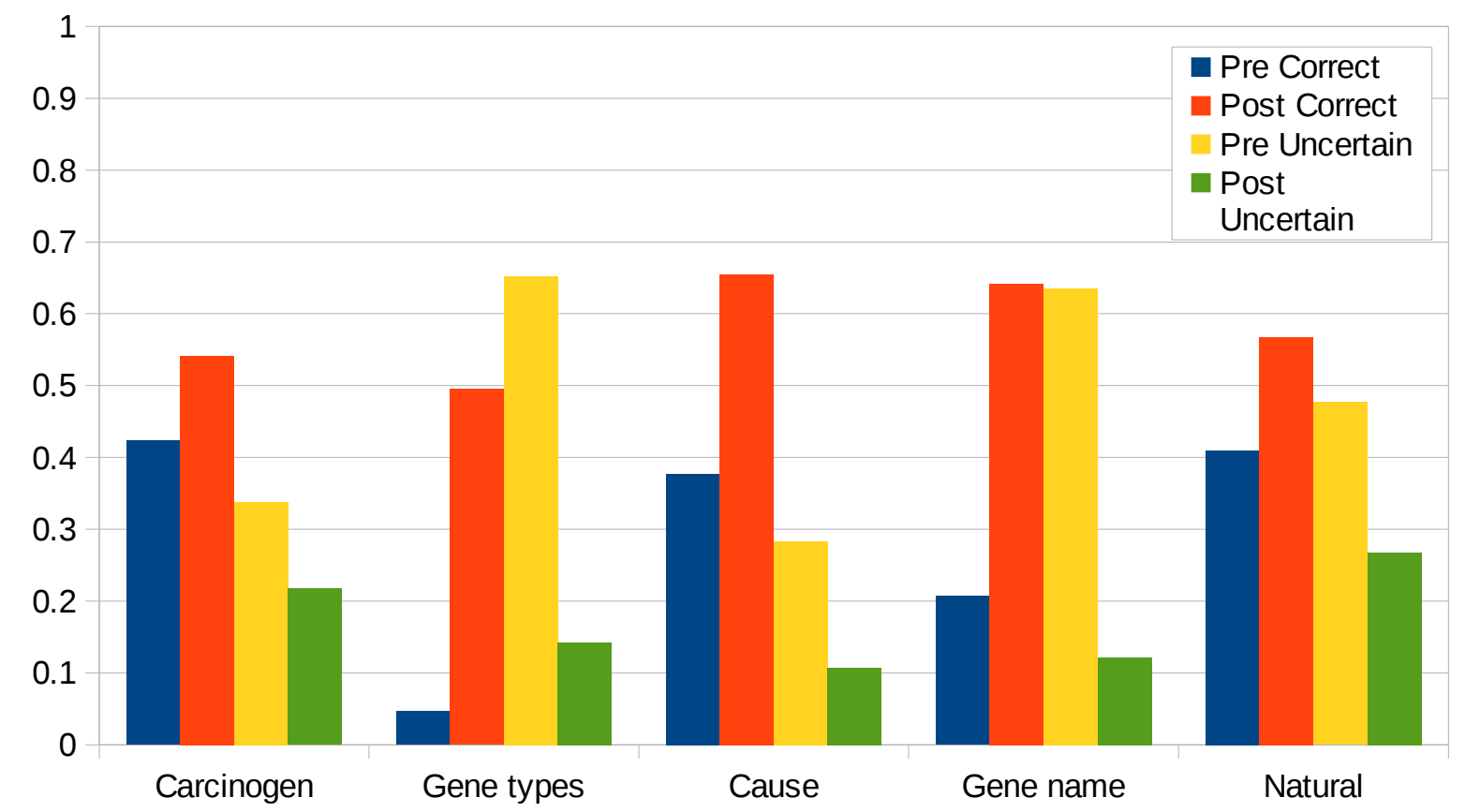

Figure 2. Plot of the results of correct and uncertain responses before and after the experiment. Data is detailed in Table 4.

In summary, there was a significant reduction in uncertainty and increase in correct cancer-relevant information recall for all of these five questions.

Correct answers to naming a carcinogen to which we are regularly exposed increased from $42 \%$ pre to 54\% post. This may seem frustratingly low, but many of the incorrect answers were substances such as asbestos, which are carcinogens but not ones to which we are regularly exposed. The most common single incorrect answer was nicotine, which is not conclusively a carcinogen (Haussmann and

230 Fariss 2016 see also Chernyavsky et al. 2015). This is a common misconception (e.g., Wilson et al. 2011) that we plan to address in future classes. The most common correct answers were UV exposure from sunlight (or equivalent, e.g., the sun) and tobacco smoke (or equivalent, e.g., cigarettes).

Similarly, the correct response of naming the two categories of cancer genes, (proto)oncogenes and tumor suppressors, increased from $4.6 \%$ pre to $50 \%$ post (pre-n 601, post-n $600, P=2.2 \times 10^{-16}$,). 
235 Many of the answers in the post survey were close but frustratingly incorrect. Examples included only giving one or the other category correctly, e.g., proto-oncogene and oncogene, being overly gene specific e.g., Ras and scrib, or category specific e.g., cell growth and DNA repair.

The correct response for the leading cause of cancer, tobacco smoke or equivalent increased dramatically from 38\% to 66\%. Lung cancer and nicotine were not counted as correct for this question.

240 Also, correct answers for naming a gene involved in cancer increased from $21 \%$ to $64 \%$. BRCA1 and Ras were common responses followed by p53 and scribbled. Oncogene, tumor suppressor, as well as only "BRCA”, were common incorrect answers. Perhaps this question should be changed to "can you name a specific cancer gene” in the future to reduce ambiguity.

Correct answers for natural carcinogens increased from 41\% to 57\% (pre-n 600, post-n 601, P= $4.9 \times 10^{-8}$, two-proportion z-test). Common correct responses were UV from sunlight, tobacco, aflatoxin, and asbestos. Common incorrect answers were nicotine, cigarettes, carbon monoxide, and methane. This is a question with some surprising misconceptions (carbon monoxide and methane) and highlights and area that can be expanded upon in providing the students with additional information.

In contrast to the previous responses, quantitative proportions appeared to be more difficult for the students to extract and/or retain from the lecture and reading.

\begin{tabular}{|l|l|}
\hline Keyword & Question \\
\hline 5 Year & What is the five year survival rate for all cancers combined in the US? \\
\hline Lifetime & What is a person's chance of being diagnosed with cancer at some point in their \\
& lives? \\
\hline Hereditary & $\begin{array}{l}\text { What fraction of cancer cases are familial or hereditary (passed down in families } \\
\text { due to genetic factors)? }\end{array}$ \\
\hline
\end{tabular}

Table 6. The keyword is only used here to guide comparisons between tables. It did not appear on the student questionnaire. 


\begin{tabular}{|l|l|l|l|l|l|}
\hline Keyword & Pre-n & Post-n & Pre- correct & Post- correct & P-value \\
\hline 5 Year & 600 & 600 & $16.5 \%$ & $16.5 \%$ & 1 \\
\hline Lifetime & 600 & 600 & $30.8 \%$ & $30.0 \%$ & 0.754 \\
\hline Hereditary & 600 & 600 & $7.17 \%$ & $41.0 \%$ & $2.2 \times 10^{-16}$ \\
\hline
\end{tabular}

Table 7. The change in proportion of correct responses out of the total was tested with a two-proportion z-test.

The one question out of three with a significant improvement focused on genetic factors. Since this was conducted as a part of a genetics class the students may have been primed to retain genetic information

260 as a byproduct of the other topics discussed in class. While not the goal of this work, and this is a small sample of questions, it raises an interesting contrast and asks how this can be addressed in the classroom. The challenges of developing quantitative skills among biology majors has been widely recognized and ways to teach and enhance quantitative skills among biology students is an active area of inquiry (e.g., Speth et al. 2010 ; Gormally et al. 2012; Hester et al. 2014). Perhaps this extends

265 beyond performance on a specific task to more passive use of quantitative information from lectures and reading.

We also asked yes or no if "the following is a risk factor for cancer”.

\begin{tabular}{|l|l|l|l|l|l|}
\hline Factor & Pre-n & Post-n & Pre- “yes” & Post- “yes” & $P$-value \\
\hline Age & 600 & 600 & $87.2 \%$ & $89.0 \%$ & 0.327 \\
\hline Cellphone use & 600 & 598 & $49.3 \%$ & $35.2 \%$ & $6.78 \times 10^{-7}$ \\
\hline Chronic & 600 & 600 & $44.7 \%$ & $49.2 \%$ & 0.118 \\
\hline inflammation & & & & & \\
\hline Obesity & 601 & 599 & $56.8 \%$ & $65.8 \%$ & $1.37 \times 10^{-3}$ \\
\hline Power lines & 600 & 600 & $21.8 \%$ & $19.8 \%$ & 0.394 \\
\hline
\end{tabular}


Table 8. The change in proportion of positive responses out of the total was tested with a two-proportion z-test.

Only two had a significant change, cellphone use and obesity, both with an increase in correct answers based on current scientific knowledge (compare cellphone use as a risk factor, Table 8, to cellphones cause cancer, Table 3; anecdotally there seemed to be an over-generalization among students that “radiation” caused cancer rather than ionizing radiation and UV light). Two factors were already predominantly correct in the pre-survey and thus had less power to detect a change. The glaring exception is chronic inflammation, which is a key component of cancer development (Coussens and Werb 2002; Hanahan and Weinberg 2011) and presents an additional point to focus on presenting to the students.

Again, we presented information specific to these questions in an indirect manner to broadly test for improvement in knowledge about cancer and cancer genetics. Instructors may wish to provide and test this information directly and inform students that they must know the answers to these specific questions between pre- and post- assessment. This will likely result in greater improvements for these specific questions; however, we feel that this does not do as well at assessing broader knowledge outside of the assigned questions. Ultimately the best strategy may be a mixed approach to assess both specifically assigned information and broader knowledge.

Finally, a question with a completely open ended component was asked “Are model organisms (like mice or Drosophila fruit flies) useful tools for studying cancer? Why or why not?” The proportion of positive responses increased from $89.9 \%$ pre- to $99.8 \%$ post- (pre-n 584 , post-n 597, $\chi^{2}=60.4$, d.f.=

$2901, \mathrm{P}=7.6 \times 10^{-15}$ ). Among the reasons given for negative responses were short life span of model organisms, genetic differences between model organisms and humans, the same risk factors cannot be studied, human specific cancer cannot be studied, flies cannot get cancer, carcinogens vary between species, and it is unethical to induce cancer in other organisms. Among the reasons given for positive 
responses were genetic and cellular similarity between humans and model organisms, model organisms are easy and cheap to maintain, short life cycles, sequenced genomes, ease of genetic manipulation, it is more ethical to study cancer in model organisms than studying it in humans, the ability to rear large numbers of genetically uniform individuals for testing and avoiding the problems of genetic heterogeneity and incomplete penetrance in human cancer cases.

Model organisms tend to be small and short lived. In many ways cancer is a disease of age,

300 accumulated DNA damage from the environment, and possibly body size. Indeed, recent insights have come from studying a range of non-traditional long-lived species (see Supplemental Discussion). Some students become aware during the course of the experiment of the discrepancy that organisms with short lifespans and limited cell divisions are used to study cancer. This is the reason causative genes in the fly are targeted in order to achieve neoplastic transformation within a short lifespan. This is not to

305 detract from model organisms (the Drosophila model has resulted in a wide range of discoveries in cancer research, Sonoshita and Cagan 2017), but the unique circumstances of each species must be kept in mind. The critical transition to a metastasizing malignant tumor in humans is thought to require additional mutations and is characterized by typical changes in gene expression, specifically the upregulation of genes that are involved in cell motility and downregulation of cell adhesion molecules

310 (e.g., Barrallo-Gimeno and Nieto 2005; Birchmeier 2005; Sedgwick and D’Souza-Schorey 2016). It is not clear that these changes occur in tumors of the fly abdomen in this experiment; however, an ambitious class might try to test this via quantifying relative RNA abundance of candidate genes. The butyrate treatment result of an increase in abdominal tumors may suggest an alternative. Butyrate is a histone deacetylase inhibitor. In humans this is thought to help prevent certain forms of cancer

315 (Donohoe et al. 2012). The initial benign tumors in this experiment are limited to the head region because of their dependence on eyeless expression of the flippase recombinase to result in mitotic recombination and loss of heterozygosity of the tumor suppressor scribbled. Histone modifications are 
a mechanism of determining cell fate. Disruptions to epigenetic programming can both disrupt normal gene expression at a subset of genes and directly contribute to a cancer phenotype (e.g., Hirabayashi and Gotoh 2010; Jones et al. 2016). These abdominal tumors may not be satellite tumors arising from metastasis of a tumor in the head but rather benign tumors arising in situ from the activation of flippase via epigenetic dysregulation. If this is the case, which remains to be seen, the fly model could prove useful in screening substances that promote tumor formation through epigenetic means (Momi et al. 2014). Regardless of the degree of similarity between the Drosophila model and human cancer, this module does serve to expose students to the most important fundamental components of cancer genetics and coveys how to use genetics tools to study these processes.

This work was originally inspired by the GMO debate and we include methods for testing the GMO status of plants by PCR. Suggestions for presentation and discussion of the relationship or lack thereof of cancer and GMOs are provided in the Supplemental Discussion. some forms of non-ionizing electromagnetic radiation (cell phones, power lines) and cancer. This is an area of active research and controversy (Hertsgaard and Dowie 2018; Landler and Keays 2018; NCI 2019). In the spirit of this CURE, there are a range of creative ways to for classrooms to test electromagnetic radiation using the Drosophila cancer model. In addition to illustrating the utility of model organisms, in this case Drosophila melanogaster, cancer biology underscores the importance of pure research. This can be summarized by three Nobel prizes in Physiology or Medicine. Peyton Rous was interested in natural history and later pathology. He investigated a tumor in a hen brought by a person to the institute where he worked. He could not have known that his work would identify oncogenic viruses and lead him on a path that also identified chemical carcinogens, two distinct mechanisms of carcinogenesis, and ultimately resulted in the 1966 Nobel Prize (Weiss and Vogt 2011). Tim Hunt was working on getting sea urchin eggs to divide 
without being fertilized and noticed an odd pattern of a protein that appeared and disappeared with each cell division. In light of the current difficulty in obtaining funding for basic research it is sobering to read Hunt (2015) and Robertson (2015), also listen to Al-Khalili (2011) for an audio interview. There were a series of chance events that led to the discovery of cyclins that control the cell cycle, difficulty in getting the scientific community to realize the significance, had implications for understanding cancer, and ultimately resulted in the 2001 Nobel Prize. More recent breakthroughs have been in the interface between the immune system and cancer, which resulted in the 2018 Nobel Prize. 'Neither of the two Nobel Prize winners, Jim Allison and Tasuku Honjo, directly set out to cure cancer - "that wasn't it at all,’ Allison has said - they were trying to understand how the immune system works’ (Davis 2020). In the process the total rates of cancer in the US peaked in 1991 and have since fallen (13\% from 1991 to 2015, NCI 2018) deaths due to cancer have also fallen (29\% from 1991 to 2017, Siegel et al. 2020), and five year survivorship has increased (26\% from 1991 to 2015, NCI 2018). A number of new tools are continuing to be developed. We should recognize the breakthroughs that stem

355 from fundamental biological research and that none of these leaps in understanding would have happened if there were not people trained in biological research. In order to understand and address cancer, support biology research and education.

\section{Acknowledgements}

We thank the students and teaching assistants of BIOL 375L Genetics Lab, University of Hawai'i at Mānoa for participating in this project. We thank Sachie Etherington and Natasha Isaac for coordinating the teaching lab. We thank Zhaotong Xu, Tahoora Pourjalali, Herena Ha, and Keisha Willis for help maintaining the fly stocks and media preparation. We thank Vanessa Reed for editing and proofreading. David Bilder, Ryan Boileau, Tian Xu, and La-Di Ming graciously provided 
Drosophila stocks.

\section{Methods}

\section{Research regulation}

This is written from the perspective of regulation within the United States; check for equivalent regulations in your own jurisdictions. Research in a classroom setting fall into a regulatory gray zone (e.g., Tomkowiak and Gunderson 2004; Callier 2012). This is also the case for using transgenic organisms in a classroom. NIH guidelines do not mention classroom settings and education in their transgenic biosafety rules (https://osp.od.nih.gov/biotechnology/nih-guidelines/). Individual institutions, as the University of Hawai`i administration has done, may choose to regulate this teaching module as laboratory research. In this case this work is registered under IBC protocol no. 18-08-93204-1A. You should check with your institute’s biosafety committee (EHSO, Environmental Health and Safety Office or equivalent) for guidance regarding classification of lab activities with genetically modified organisms.

A CO 2 based fly anesthetization system (a pressurized $\mathrm{CO}_{2}$ source, needle, pad, paintbrushes, dissecting microscope, etc.) is highly recommended for working with Drosophila in the classroom. Fly stocks are maintained on standard yeast-glucose agar media in trays of vials with cotton stoppers.

Two complex genetic lines of flies, designed to model tumor metastasis, are crossed together:

Line 2: y[-], w[-], ey-FLP; Act-Gal4; UAS-GFP S56T; FGT82B; Tub6-Gal80

These lines make use of the GAL4/GAL80/UAS expression control system (Duffy 2002) and the FLP/ 
FRT system (Golic and Lindquist 1989; Wu and Luo 2006) activated in the larval head to make double stranded DNA cuts at specific chromosomal positions resulting in mitotic recombination. Furthermore, the oncogene Ras[V12] gain-of-function hypermorph is expressed simultaneously with a loss of heterozygosity, as a result of mitotic recombination, of a tumor suppressor scrib[-] amorph which triggers precancerous and cancerous cell behavior. The loss of heterozygosity also results in the expression of Green Fluorescent Protein (GFP) which marks the precancerous cells. GFP expressing cells were visualized with a Nightsea stereo-microscope fluorescence adapter

395 (https://www.nightsea.com) with a 440-460 nm excitation light and 500-560 nm emission filter. A MiniVID eyepiece camera was used to record examples.

See Supplemental methods for the fly food recipe used.

The vials were labeled with 10 different numbers. Five numbers corresponded to controls and five numbers corresponded to the food additive to be tested. The numbers overlapped in sequence (e.g., control: 3, 4, 6, 8, 9; test: $1,2,5,7,10)$ The key for decoding the food was kept by the lab manager and not made available to either the students scoring the larvae or to the teaching assistants and class instructor until after the experiment had finished and the final numbers were tabulated (i.e., a doubleblind experiment).

Line 1 and line 2 were crossed to each other using standard Drosophila lab technique (e.g.,

405 Greenspan 2004) and allowed to lay eggs on the food for three days before the adults were cleared from the vial. After one week the third instar larvae were scored. The food can autofluoresce so it is recommended that the larvae be washed briefly in water before scoring. The presence of a clear point or points of GFP expression in the posterior 2/3 of the larvae were recorded as a metastasis.

It is necessary that a control be run in parallel with each treatment to be tested rather than comparing to previous control results or current and prior controls in aggregate. The GAL4 system is sensitive to environmental conditions such as temperature which may vary between semesters. The use 
of insect incubators, which can be temperature and light controlled (e.g., 14:10 hr light/dark at 24 C), are recommended if possible.

\section{GMO detection}

Students were asked to bring papaya samples (commonly grown here in Hawai 'i) from a wide range of sources (grocery store, farmer's markets, homegrown) and to attempt to include plants not thought to be genetically modified. The class instructors were also able to obtain GMO and non-GMO papaya. Fruits were labeled with tape and a marker and stored in a refrigerator. A small section of the fruit skin,

420 less than a square centimeter, was removed and DNA was extracted (Qiagen DNeasy plant kit). This was used for PCR (see Merritt et al. 2008 for a way to conduct PCR if a thermocycler is not available). The following PCR primers have been found to perform well in the classroom and can be ordered from online DNA oligo synthesis services (we used https://www.idtdna.com/).

Standard rbcL DNA barcoding primers were used as a positive PCR control (Kress and Erickson 2007).

425 rbcL-a-f 5’-ATGTCACCACAAACAGAGACTAAAGC

rbcL-a-r 5’-GTAAAATCAAGTCCACCRCG

The 35S promoter from the cauliflower mosaic virus (CaMV) is present in a wide range of genetically modified crop plants (including papaya) and provides a useful way to screen for GMO status by PCR (e.g., Hurst et al. 1999 and references therein).

430 CaMV35Sf 5'-GCTCCTACAAATGCCATCA

\section{CaMV35Sr 5'-GATAGTGGGATTGTGCGTCA}

The temperature cycling scheme 1 was used for both PCR reactions (this allows them to be run simultaneously in the same thermocycler). This temperature cycling is optimized for the 35S primer pair. If two different temperature cycling schemes are used the scheme 2 should be used for the rbcL 435 primer pair. 
Temperature cycling 1: 95 C 3 min, 33 cycles of (94 C 20 s, 54 C 40 s, 72 C 1 min), 72 C 3 min Temperature cycling 2: 95 C 3 min, 33 cycles of (94 C 30 s, 55 C 30 s, 72 C 1 min), 72 C 10 min The PCR reactions are designed for a $20 \mu$ final volume. A 5X master mix is provided to the students who must dilute it with purified water and add the correct primer pair and a $1 \mu$ l DNA sample to a final

$4401 \mathrm{X}$ concentration of $200 \mu \mathrm{M}$ dNTP mix, $1.5 \mathrm{mM} \mathrm{MgCl}$, and $0.05 \mathrm{U} / \mu \mathrm{l}$ Taq polymerase, and $1 \mu \mathrm{M}$ primer mix.

Three PCR reactions were set up for each sample: a positive control with the rbcL primers, a negative control with $1 \mu \mathrm{l}$ purified water substituted for the DNA sample, and the GMO-test PCR with 35S primers.

\section{Food additives}

GMO and non-GMO food:

Commercially available Rainbow Papaya that was confirmed by PCR to be genetically modified and a papaya from Kumu Farms, Maui that was confirmed by PCR to not be genetically modified were used.

The whole fruit was washed with filtered purified water and wiped down with $70 \%$ ethanol to sterilize the surface. Then the fruits with the skin and without the seeds were pureed, approximately $1 / 2$ kilogram of fruit puree was added to the Drosophila food.

Noni juice:

375 ml of commercially available "Puna Noni Naturals Noni Juice" Noni Connection, Inc. (“100\%

455 Pure Hawaiian Noni Juice”) was used.

Vitamin supplement:

$0.08 \mathrm{~g}$ of ground Telovites (Telovites, West Martin, Inc.) was added. The ingredients list of the Telovites used is copied here. "Vitamin A (as acetate, beta-carotene) Vitamin C (as ascorbic acid, calcium ascorbate) Vitamin D3 (as cholecalciferol) Vitamin E (as d-alpha tocopheryl succinate and 

(as Niacinamide) Vitamin B6 (as pyridoxine $\mathrm{HCl}$ ) Folic acid Vitamin B12 (as cyanocobalamin) Biotin Pantothenic Acid (as d-calcium pantothenate) Calcium (as carbonate, dibasic calcium phosphate, citrate, ascorbate) Phosphorus (as dibasic calcium phosphate) Iodine (potassium iodide, kelp) Magnesium (as oxide, citrate) Zinc (as amino acid chelate) Selenium (as selenomethionine) Copper (as sodium molybdate) Chloride (as potassium chloride) Potassium (as potassium chloride) Green Tea leaf extract Standardized to 90\% polyphenols Chlorella (Chlorella vulgaris) Resveratrol (providing $30 \mathrm{mg}$ trans-resveratrol) Choline bitartrate Astragalus membranaceus Providing Polysaccharides 40 mg LCarnosine Inositol Grape seed extract (85-95\% OPC) Lycopene Lutein Silicon (as sodium metasilicate) Boron Vanadium (as vanadyl sulfate) Nickel (as nickel sulfate).”

Styrofoam:

$17.78 \mathrm{~g}$ of ground up commercially available styrofoam/polystyrene plates were added to the food. Butyrate:

750 mg of sodium butyrate (Sigma-Aldrich B5887-250MG) were added.

475 Roundup:

$12.5 \mathrm{ml}$ of commercially available “Roundup Ready-To-Use Weed \& Grass Killer III” (2.0\% glyphosate isopropylamine salt, 2.0\% pelargonic acid \& related fatty acids, $96.0 \%$ other ingredients) was added to the food.

\section{References}

ACS (American Cancer Society). (2014). Lifetime risk of developing or dying from cancer. https://www.cancer.org/cancer/cancer-basics/lifetime-probability-of-developing-or-dying-from- 
cancer.html

Al-Khalili, J. (2011). The Life Scientific: Tim Hunt. BBC Radio 4. BBC.

Anonymous. (2018). 'The food supplement that ruined my liver' BBC News https://www.bbc.com/news/ stories-45971416

Auchincloss, L. C., Laursen, S. L., Branchaw, J. L., Eagan, K., Graham, M., Hanauer, D. I., ... \& Towns, M. (2014). Assessment of course-based undergraduate research experiences: a meeting report. CBE—Life Sciences Education, 13(1), 29-40.

Barrallo-Gimeno, A., \& Nieto, M. A. (2005). The Snail genes as inducers of cell movement and survival: implications in development and cancer. Development, 132(14), 3151-3161.

Barrell, A. (2019). What are the pros and cons of GMO foods? Medical News Today https://www.medicalnewstoday.com/articles/324576.php

495 Birchmeier, W. (2005). Cell adhesion and signal transduction in cancer. EMBO Reports, 6(5), 413-417. Blasco, M. A. (2005). Telomeres and human disease: ageing, cancer and beyond. Nature Reviews Genetics, 6(8), 611.

Brown, A. C. (2012). Anticancer activity of Morinda citrifolia (Noni) fruit: a review. Phytotherapy Research, 26(10), 1427-1440.

500 Brownell, S. E., Hekmat-Scafe, D. S., Singla, V., Chandler Seawell, P., Conklin Imam, J. F., Eddy, S. L., ... \& Cyert, M. S. (2015). A high-enrollment course-based undergraduate research experience improves student conceptions of scientific thinking and ability to interpret data. CBE-Life Sciences Education, 14(2), ar21.

Bultman, S. J. (2017). Interplay between diet, gut microbiota, epigenetic events, and colorectal cancer. Molecular Nutrition \& Food Research, 61(1), 1500902.

Cabin, R. J., \& Mitchell, R. J. (2000). To Bonferroni or not to Bonferroni: when and how are the 
questions. Bulletin of the Ecological Society of America, 81(3), 246-248.

Callier, S. L. (2012). Swabbing students: should universities be allowed to facilitate educational DNA testing? The American Journal of Bioethics, 12(4), 32-40.

510 Casassus, B. (2013). Study linking GM maize to rat tumours is retracted. Nature News. doi:10.1038/nature.2013.14268

Charles, D. (2019). Safe Or Scary? The Shifting Reputation Of Glyphosate, AKA Roundup. NPR Morning Edition. https://www.npr.org/sections/thesalt/2019/05/30/727914874/safe-or-scary-theshifting-reputation-of-glyphosate-aka-roundup

515 Chen, J., Call, G. B., Beyer, E., Bui, C., Cespedes, A., Chan, A., ... \& Deravanesian, A. (2005). Discovery-based science education: functional genomic dissection in Drosophila by undergraduate researchers. PLoS Biology, 3(2), e59.

Chen, F., M. Du, J. B. Blumberg, K. K. H. Chui, et al. (2019). Association Among Dietary Supplement Use, Nutrient Intake, and Mortality Among U.S. Adults: A Cohort Study. Annals of Internal Medicine 170(9): 604-613.

Chernyavsky, A. I., Shchepotin, I. B., Galitovkiy, V., \& Grando, S. A. (2015). Mechanisms of tumorpromoting activities of nicotine in lung cancer: synergistic effects of cell membrane and mitochondrial nicotinic acetylcholine receptors. BMC Cancer, 15(1), 152.

Christensen, M., J. Vestergaard, F. d’Amore, J. Gørløv, et al. (2018) Styrene Exposure and Risk of 525 Lymphohematopoietic Malignancies in 73,036 Reinforced Plastics Workers. Epidemiology 29(3):342-351

Coussens, L. M., \& Werb, Z. (2002). Inflammation and cancer. Nature, 420(6917), 860.

Davis, D. (2020). Why your immune system is key in the fight against cancer. WIRED Health https://www.wired.co.uk/article/immune-system-cancer

530 Desai, K. V., Gatson, S. N., Stiles, T. W., Stewart, R. H., Laine, G. A., \& Quick, C. M. (2008). 
Integrating research and education at research-extensive universities with research-intensive communities. Advances in Physiology Education, 32(2), 136-141.

Donohoe, D. R., Collins, L. B., Wali, A., Bigler, R., Sun, W., \& Bultman, S. J. (2012). The Warburg effect dictates the mechanism of butyrate-mediated histone acetylation and cell proliferation. Molecular Cell, 48(4), 612-626.

Duffy, J. B. (2002). GAL4 system in Drosophila: a fly geneticist's Swiss army knife. Genesis, 34(12), $1-15$.

Ferreira, S. A., Pitz, K. Y., Manshardt, R., Zee, F., Fitch, M., \& Gonsalves, D. (2002). Virus coat protein transgenic papaya provides practical control of papaya ringspot virus in Hawaii. Plant Disease, 86(2), 101-105.

Fox, E. G. (2019). Food packaging is full of toxic chemicals - here's how it could affect your health. The Guardian https://www.theguardian.com/us-news/2019/may/28/plastics-toxic-americachemicals-packaging

Goldey, E. S., Abercrombie, C. L., Ivy, T. M., Kusher, D. I., Moeller, J. F., Rayner, D. A., ... Spivey, N. W. (2012). Biological inquiry: A new course and assessment plan in response to the call to transform undergraduate biology. CBE—Life Sciences Education, 11, 353- 363.

Goldstein, D. A. (2014). Tempest in a tea pot: How did the public conversation on genetically modified crops drift so far from the facts? Journal of Medical Toxicology, 10(2), 194-201.

Golic, K. G., \& Lindquist, S. (1989). The FLP recombinase of yeast catalyzes site-specific recombination in the Drosophila genome. Cell, 59(3), 499-509.

Gonsalves, D. (1998). Control of papaya ringspot virus in papaya: a case study. Annual Review of Phytopathology, 36(1), 415-437.

Gormally, C., Brickman, P., \& Lutz, M. (2012). Developing a test of scientific literacy skills (TOSLS): Measuring undergraduates' evaluation of scientific information and arguments. CBE—Life Sciences 
Greenspan, R. J. (2004) Fly Pushing: The Theory and Practice of Drosophila Genetics. 2nd Edition. Cold Spring Harbor Laboratory Press, Cold Spring Harbor, New York. ISBN 978-0879697112

Grunewald, W., \& Bury, J. (2013). Comment on" Long term toxicity of a Roundup herbicide and a Roundup-tolerant genetically modified maize" by Séralini et al. Food and Chemical Toxicology, 53, 447-448.

Hammond, B., Goldstein, D. A., \& Saltmiras, D. (2013). Response to original research article, 'Long term toxicity of a Roundup herbicide and a Roundup-tolerant genetically modified maize’. Food Chem. Toxicol., 53, 459-464

Hanahan, D., \& Weinberg, R. A. (2011). Hallmarks of cancer: the next generation. Cell, 144(5), 646674.

Handelsman, Jo, Diane Ebert-May, Robert Beichner, Peter Bruns, Amy Chang, Robert DeHaan, Jim Gentile et al. (2004) "Scientific teaching." Science : 521-522.

Harrison M, Dunbar D, Ratmansky L, Boyd K, Lopatto D (2011). Classroom-based science research at the introductory level: changes in career choices and attitude. CBE Life Sci Educ 10, 279-286.

Haussmann, H. J., \& Fariss, M. W. (2016). Comprehensive review of epidemiological and animal studies on the potential carcinogenic effects of nicotine per se. Critical Reviews in Toxicology, 46(8), 701-734.

Hayes, D. D. W. (2013). Comments on “Long term toxicity of a Roundup herbicide and a Rounduptolerant genetically modified maize”. Food and Chemical Toxicology, 53, 443-444.

575 Hertsgaard \& Dowie (2018). The inconvenient truth about cancer and mobile phones. The Guardian, published online https://www.theguardian.com/technology/2018/jul/14/mobile-phones-cancerinconvenient-truths

Hester, S., Buxner, S., Elfring, L., \& Nagy, L. (2014). Integrating quantitative thinking into an 
introductory biology course improves students’ mathematical reasoning in biological contexts. CBE -Life Sciences Education, 13(1), 54-64.

Hirabayashi, Y., \& Gotoh, Y. (2010). Epigenetic control of neural precursor cell fate during development. Nature Reviews Neuroscience, 11(6), 377.

Hunt, T. (2015). Pursuing the impossible: an interview with Tim Hunt. BMC Biology, 13(1), 64.

Hurst, C. D., Knight, A., \& Bruce, I. J. (1999). PCR detection of genetically modified soya and maize in foodstuffs. Molecular Breeding, 5(6), 579-586.

Jones, P. A., Issa, J. P. J., \& Baylin, S. (2016). Targeting the cancer epigenome for therapy. Nature Reviews Genetics, 17(10), 630.

Jordan, T. C., Burnett, S. H., Carson, S., Caruso, S. M., Clase, K., DeJong, R. J., ... \& Findley, A. M. (2014). A broadly implementable research course in phage discovery and genomics for first-year undergraduate students. MBio, 5(1), e01051-13.

Kallis, T. (2013) Papaya: A GMO success story. Hawaii Tribune Herald, June 10, 2013. Published online http://hawaiitribune-herald.com/sections/news/local-news/papaya-gmo-success-story.html Kress WJ, Erickson DL (2007) A Two-Locus Global DNA Barcode for Land Plants: The Coding rbcL Gene Complements the Non-Coding trnH-psbA Spacer Region. PLoS ONE 2(6)

595 Landler, L., \& Keays, D. A. (2018). Cryptochrome: The magnetosensor with a sinister side? PLoS Biology, 16(10), e3000018.

Liao, C., \& Kannan, K. (2013). Concentrations and profiles of bisphenol A and other bisphenol analogues in foodstuffs from the United States and their implications for human exposure. Journal of Agricultural and Food Chemistry, 61(19), 4655-4662.

600 Merritt, R. B., Bierwert, L. A., Slatko, B., Weiner, M. P., Ingram, J., Sciarra, K., \& Weiner, E. (2008). Tasting phenylthiocarbamide (PTC): a new integrative genetics lab with an old flavor. The American Biology Teacher, 70(5). 
Ming, R., Hou, S., Feng, Y., Yu, Q., Dionne-Laporte, A., Saw, J. H., ... \& Salzberg, S. L. (2008). The draft genome of the transgenic tropical fruit tree papaya (Carica papaya Linnaeus). Nature, 452(7190), 991.

Momi, N., Kaur, S., Rachagani, S., Ganti, A. K., \& Batra, S. K. (2014). Smoking and microRNA dysregulation: a cancerous combination. Trends in Molecular Medicine, 20(1), 36-47.

NCI (National Cancer Institute). 2003. Lag Time.

http://press2.nci.nih.gov/sciencebehind/cancer/cancer31.htm

610 NCI (National Cancer Institute). 2018. Surveillance, Epidemiology, and End Results (SEER) Program. https://seer.cancer.gov/

NCI (National Cancer Institute). 2019. Electromagnetic Fields and Cancer.

https://www.cancer.gov/about-cancer/causes-prevention/risk/radiation/electromagnetic-fields-factsheet

615 Pagliarini, R. A., \& Xu, T. (2003). A genetic screen in Drosophila for metastatic behavior. Science, 302(5648), 1227-1231.

Panchin, A. Y. (2013). Toxicity of roundup-tolerant genetically modified maize is not supported by statistical tests. Food and Chemical Toxicology, (53), 475.

Peterson, M. 2019, California Couple Awarded \$2 Billion In Roundup Cancer Trial. NPR Morning Edition (https://www.npr.org/2019/05/14/723134988/california-couple-awarded-2-billion-inroundup-cancer-trial)

Piskounova, E., Agathocleous, M., Murphy, M. M., Hu, Z., Huddlestun, S. E., Zhao, Z., ... \& Morrison, S. J. (2015). Oxidative stress inhibits distant metastasis by human melanoma cells. Nature, 527(7577), 186.

625 Retzbach, A., \& Maier, M. (2015). Communicating scientific uncertainty: Media effects on public engagement with science. Communication Research, 42(3), 429-456. 
Robertson, R. (2015). The discovery of cyclin: the unknown and the unknowable. On Biology https://blogs.biomedcentral.com/on-biology/2015/08/21/discovery-cyclin-unknown-unknowable/

Rodenbusch, S. E., Hernandez, P. R., Simmons, S. L., \& Dolan, E. L. (2016). Early engagement in course-based research increases graduation rates and completion of science, engineering, and mathematics degrees. CBE—Life Sciences Education, 15(2), ar20.

Romeis, J., McLean, M. A., \& Shelton, A. M. (2013). When bad science makes good headlines: Bt maize and regulatory bans. Nature Biotechnology, 31(5), 386.

Russell, S. H., Hancock, M. P., \& McCullough, J. (2007). Benefits of undergraduate research experiences. Science, 316(5824), 548-549.

Schultz, H. (2014). Despite extensive cancer claims, Noni fruit purveyor receives only warning letter from FDA. Nutra. https://www.nutraingredients-usa.com/Article/2014/07/23/Despite-extensivecancer-claims-Noni-fruit-purveyor-receives-only-warning-letter-from-FDA

Sedgwick, A., \& D’Souza-Schorey, C. (2016). Wnt signaling in cell motility and invasion: drawing parallels between development and cancer. Cancers, 8(9), 80.

Séralini, G.-E., Clair, E., Mesnage, R., Gress, S., Defarge, N., Malatesta, M., ... de Vendômois, J. S. (2012). Long term toxicity of a Roundup herbicide and a Roundup-tolerant genetically modified maize. Food and Chemical Toxicology, 50, 4221-4231. doi:10.1016/j.fct.2012.08.005

Shahab, L., McGowan, J. A., Waller, J., \& Smith, S. G. (2018). Prevalence of beliefs about actual and mythical causes of cancer and their association with socio-demographic and health-related characteristics: Findings from a cross-sectional survey in England. European Journal of Cancer, 103, 308-316.

Siegel, R. L., Miller, K. D., \& Jemal, A. (2020). Cancer statistics, 2020. CA: A Cancer Journal for 
Clinicians, 0(0), 1-24. doi: 10.3322/caac.21590. Available online at cacancerjournal.com

650 Sonoshita, M., \& Cagan, R. L. (2017). Modeling human cancers in Drosophila. In Current Topics in Developmental Biology (Vol. 121, pp. 287-309). Academic Press.

Soto AM, \& Sonnenschein C (2010). Environmental causes of cancer: Endocrine disruptors as carcinogens. Nature Reviews Endocrinology 6 (7): 363-70.

Speth, E. B., Momsen, J. L., Moyerbrailean, G. A., Ebert-May, D., Long, T. M., Wyse, S., \& Linton, D. (2010). 1, 2, 3, 4: infusing quantitative literacy into introductory biology. CBE-Life Sciences Education, 9(3), 323-332.

Tomkowiak, J. M., \& Gunderson, A. J. (2004). To IRB or not to IRB? Academic Medicine, 79(7), 628632.

Villegas, S. N. (2019). One hundred years of Drosophila cancer research: no longer in solitude. Disease Models \& Mechanisms, 12(4), dmm039032.

Wallace, A. H. (2014). Editor in Chief of Food and Chemical Toxicology answers questions on retraction. Food and Chemical Toxicology, 65, 394-395.

Wei CA, Woodin T. Undergraduate research experiences in biology: alternatives to the apprenticeship model. CBE Life Sci Educ. 2011;10:123-131.

Weiss, R. A., \& Vogt, P. K. (2011). 100 years of Rous sarcoma virus. Journal of Experimental Medicine, 208(12), 2351-2355.

Willeit, P., Willeit, J., Mayr, A., Weger, S., Oberhollenzer, F., Brandstätter, A., ... \& Kiechl, S. (2010). Telomere length and risk of incident cancer and cancer mortality. Jama, 304(1), 69-75.

Willoughby, L. F., Schlosser, T., Manning, S. A., Parisot, J. P., Street, I. P., Richardson, H. E., ... \& Brumby, A. M. (2013). An in vivo large-scale chemical screening platform using Drosophila for anti-cancer drug discovery. Disease Models \& Mechanisms, 6(2), 521-529.

Wilson, N., Peace, J., Edwards, R., \& Weerasekera, D. (2011). Smokers commonly misperceive that 
nicotine is a major carcinogen: National survey data. Thorax, 66(4), 353-354.

Wood W. B. (2003). Inquiry-based undergraduate teaching in the life sciences at large research universities: a perspective on the boyer commission report. Cell Biol Educ 2: 112-116.

Wu, J. S., \& Luo, L. (2006). A protocol for mosaic analysis with a repressible cell marker (MARCM) in Drosophila. Nature Protocols, 1(6), 2583.

\section{Supplemental Discussion}

\section{Lecture presentation suggestions}

Cancer genetics is a natural extension of topics such as mitosis, cell cycle control, and gene product interactions (e.g., pRB, E2F, Cyclin D1, and Cdk4; Tyson et al. 2001; Davidich and Bornholdt 2008; Figure 1 of Akin et al. 2014) and can be introduced fairly early in a typical genetics class. There are also aspects of developmental genetics that are relevant background for cancer genetics. Cells in

685 multicellular organisms depend extensively on signals from other cells for growth, cell fate, and cell death signals (Notch and Wnt are good examples; e.g., Artavanis-Tsakonas et al. 1999; Loh et al. 2016). Understanding the role of the cellular environment and components like p53 and TOR in growth signals, growth inhibition, and programmed cell death is an important aspect of cancer development (Ashcroft and Vousden 1999; Fingar and Blenis 2004; Hanahan and Weinberg 2009; Hanahan and Weinberg 2011; Pacheco et al. 2014). Finally, cancer evasion of the immune system and new cancer therapies based on utilizing the immune system should be illustrated (e.g., Couzin-Frankel 2013; Muenst et al. 2016).

Epidemiological data provide insights into cancer causes and development (Ames et al. 1995). The change in rates of deaths due to cancer over the last century illustrate the effects of smoking on lung cancer and likely effects of changes in food preservation on stomach cancer (Peto et al. 2000; 
Figure 8 of Siegel et al. 2016). The 20 to 30 year lag between changes in the rates of smoking and lung cancer (NCI 2003) is especially informative as to the time it takes for cancer to develop after exposure to risk factors. This illustrates that cancer development is a long process of trial and error by mutations, not the least of which is maintaining evasion of the immune system by a subset of successful cells.

700 Finally, cancer incidence plotted by age illustrates that cancer is also a disease of aging with rates increasing dramatically after 55 years of age (CRUK 2019).

This teaching module was originally inspired by a genetics classroom (BIOL 375) discussion of the controversial results of Seralini et al. (2012), which claimed that feed containing genetically modified (GM) crop plants caused cancer. This publication resulted in widespread media impact

705 (Romeis et al. 2013 and references therein) and controversy (e.g., Casassus 2013). The class discussion included pointing out the disconnect between statements made in the publication and the results provided, additional information such as the rates of tumors that occur in the type of rats used, as well as psychological and social issues such as confirmation bias and framing effects in the media. Irrational fear of new technologies (e.g., cell phones, nanotechnology, artificial intelligence) among a subset of the population makes people receptive to speculation that some of these new technologies are responsible for problems with cryptic origins like cancer. While there was no mechanistic reason to infer that consumption of GM produce caused cancer (in fact quite the opposite in some cases, e.g. Munkvold et al. 1999; Dowd 2000), the students remained divided on the core question; with very limited sample sizes was there a reasonable amount of evidence in either direction, that GM organisms are associated with or not associated with increased cancer rates? The point was brought up that, as scientists, we should conduct a similar study and test this for ourselves in the teaching lab with more statistical power from a larger sample size.

If you and/or your students choose to test GMOs, we encourage you to also include a discussion of mechanistic reasons why specific GMO food could be harmful (e.g., Nordlee et al. 1996), protective 
720 (e.g., Dowd 2000; Singh and Bhalla 2008; Jean-Yves et al. 2017), or neither (e.g., Snell et al. 2012) as well as larger questions such as the idea of what is "natural” in the context of transgenics and engineered food (e.g., Dubcovsky and Dvorak 2007; Pace et al. 2008; Hehemann et al. 2010; Kyndt et al. 2015; Soucy et al. 2015) and some of the social issues involved (e.g., McGray 2002; Enserink 2008; Stone 2010; Lynas 2013; Fischer et al. 2015). This also has implications for the GMO labeling debate

725 (e.g., Roff 2009; Prentice 2018), which is also an appropriate point to discuss in the classroom.

Part of the philosophy behind designing this lab was to illustrate the value of model organisms. However, recent insights have also come from studying a range of non-model species. This provides an opportunity to broaden the discussion beyond medical applications to an evolutionary context (both within tumors, Vitale et al. 2019, boundaries to gene flow and speciation, Schartl 2008, and across the tree of life, Aktipis et al. 2015; Albuquerque et al. 2018). First of all is the observation, known as Peto’s paradox, that large and/or long lived organisms do not have higher rates of cancer despite having more cells and opportunities for DNA damage. These organisms have evolved strategies of cancer suppression such as increased copies of p53 in elephants (Callaway 2015 and references therein), a unique extracellular environment in naked mole rats (Toole 2004; Tian et al. 2013), and cell walls in plants (Doonan and Sablowski 2010).

Another excellent case of cancer and evolution is found among transmissible cancers. Transmissible cancer has conservation implications in the Tazmanian Devil and helps to illustrate the dangers of low genetic diversity of the immune system (Bostanci 2005; O’Neill 2010; Woods et al. 2015; Caldwell and Siddle 2017). Transmissible cancer has also been found among shellfish and may be more common than realized in marine systems (Metzger et al. 2015; Metzger et al. 2016). Some transmissible cancers may be tens of thousands of years old, evolving along with their host and becoming established in new species (Murchison et al. 2015; Strakova and Murchison 2015). Carried to an extreme, there is a hypothesis that some parasitic animals, Myxosporea, may have evolved from 
transmissable cancer (Panchin et al. 2019).

Cancer is a breakdown of cellular cooperation in multicellular organisms (Aktipis et al. 2015).

We can further broaden our focus and ask what cancer-like dynamics would look like in superorganisms or even social organizations. A mutant lineage in an ant species, Pristomyrmex punctatus, only produces queens which migrates to new colonies to live off of the workers and avoid local extinction within the host colony (Dobata et al. 2011); this is essentially cancer on a super-organism

750 level with analogs of gain of function mutations, loss of regulation, and metastasis. In human societies policing is used to suppress competition and enforce cooperation in groups of individuals (e.g. Frank 2003; West et al. 2007); which has parallels with the roles of tumor suppressors ensuring cellular cooperation - these perspectives and analogues may aide students development of cancer concepts and inspire new directions.

755 References

Akin, S., Babacan, T., Sarici, F., \& Altundag, K. (2014). A novel targeted therapy in breast cancer: cyclin dependent kinase inhibitors. Jbuon, 19(1), 42-46.

Aktipis, C. A., Boddy, A. M., Jansen, G., Hibner, U., Hochberg, M. E., Maley, C. C., \& Wilkinson, G. S. (2015). Cancer across the tree of life: cooperation and cheating in multicellularity. Philosophical Transactions of the Royal Society B: Biological Sciences, 370(1673), 20140219.

Albuquerque, T. A., Drummond do Val, L., Doherty, A., \& de Magalhães, J. P. (2018). From humans to hydra: patterns of cancer across the tree of life. Biological Reviews, 93(3), 1715-1734.

Ames, B. N., Gold, L. S., \& Willett, W. C. (1995). The causes and prevention of cancer. Proceedings of the National Academy of Sciences, 92(12), 5258-5265.

765 Artavanis-Tsakonas, S., Rand, M. D., \& Lake, R. J. (1999). Notch signaling: cell fate control and signal integration in development. Science, 284(5415), 770-776.

Ashcroft, M., \& Vousden, K. H. (1999). Regulation of p53 stability. Oncogene, 18(53), 7637. 
Bostanci, A. (2005) A devil of a disease. Science 307: 1035-1035.

Caldwell, A., \& Siddle, H. V. (2017). The role of MHC genes in contagious cancer: the story of Tasmanian devils. Immunogenetics, 69(8-9), 537-545.

Callaway, E. (2015). How elephants avoid cancer. Nature, 1038, 18534.

Casassus, B. (2013). Study linking GM maize to rat tumours is retracted. Nature News. doi:10.1038/nature.2013.14268

Couzin-Frankel, J. (2013). Cancer immunotherapy. Science 342: 1432-1433.

CRUK (Cancer Research UK) 2019 https://www.cancerresearchuk.org/health-professional/cancerstatistics/incidence/age

Davidich, M. I., \& Bornholdt, S. (2008). Boolean network model predicts cell cycle sequence of fission yeast. PLoS ONE, 3(2), e1672.

Dobata, S., Sasaki, T., Mori, H., Hasegawa, E., Shimada, M., \& Tsuji, K. (2011). Persistence of the single lineage of transmissible ‘social cancer’in an asexual ant. Molecular Ecology, 20(3), 441-455.

Doonan, J. H., \& Sablowski, R. (2010). Walls around tumours-why plants do not develop cancer. Nature Reviews Cancer, 10(11), 794.

Dowd, P. F. (2000). Indirect reduction of ear molds and associated mycotoxins in Bacillus thuringiensis corn under controlled and open field conditions: utility and limitations. Journal of Economic Entomology, 93(6), 1669-1679.

Dubcovsky, J., \& Dvorak, J. (2007). Genome plasticity a key factor in the success of polyploid wheat under domestication. Science, 316(5833), 1862-1866.

Enserink, M. Tough lessons from golden rice. Science, 320(5875):468-471,2008.

Fingar, D. C., \& Blenis, J. (2004). Target of rapamycin (TOR): an integrator of nutrient and growth factor signals and coordinator of cell growth and cell cycle progression. Oncogene, 23(18), 3151.

Fischer, K., Ekener-Petersen, E., Rydhmer, L., \& Björnberg, K. (2015). Social impacts of GM crops in 
agriculture: A systematic literature review. Sustainability, 7(7), 8598-8620.

Frank, S. A. (2003). Repression of competition and the evolution of cooperation. Evolution, 57(4), 693705.

Hanahan, D., \& Weinberg, R. A. (2000). The hallmarks of cancer. Cell, 100(1), 57-70.

Hanahan, D., \& Weinberg, R. A. (2011). Hallmarks of cancer: the next generation. Cell, 144(5), 646674.

Hehemann, J. H., Correc, G., Barbeyron, T., Helbert, W., Czjzek, M., \& Michel, G. (2010). Transfer of carbohydrate-active enzymes from marine bacteria to Japanese gut microbiota. Nature, 464(7290), 908.

Jean-Yves Paul, Harjeet Khanna, Jennifer Kleidon, Phuong Hoang, Jason Geijskes, Jeff Daniells, Ella Zaplin, Yvonne Rosenberg, Anthony James, Bulukani Mlalazi, Pradeep Deo, Geofrey Arinaitwe, Priver Namanya, Douglas Becker, James Tindamanyire, Wilberforce Tushemereirwe, Robert Harding, James Dale. Golden bananas in the field: elevated fruit pro-vitamin A from the expression of a single banana transgene. Plant Biotechnology Journal, 2017; 15 (4): 520

Kyndt, T., Quispe, D., Zhai, H., Jarret, R., Ghislain, M., Liu, Q., ... \& Kreuze, J. F. (2015). The genome of cultivated sweet potato contains Agrobacterium T-DNAs with expressed genes: an example of a naturally transgenic food crop. Proceedings of the National Academy of Sciences, 112(18), 58445849.

810 Loh, K. M., van Amerongen, R., \& Nusse, R. (2016). Generating cellular diversity and spatial form: Wnt signaling and the evolution of multicellular animals. Developmental Cell, 38(6), 643-655. Lynas, M. (2013). The true story about who destroyed a genetically modified rice crop. Future Tense: ASU—New America - Slate. Published online https://slate.com/technology/2013/08/golden-riceattack-in-philippines-anti-gmo-activists-lie-about-protest-and-safety.html

815 McGray, D. (2002). Biotech’s black market. Mother Jones. September/October Issue. Published online 
http://www.motherjones.com/politics/2002/09/biotechs-black-market.

Metzger MJ, Reinisch C, Sherry J, et al. (2015) Horizontal transmission of clonal cancer cells causes leukemia in soft-shell clams. Cell 161:255-263.

Metzger MJ, Villalba A, Carballal MJ et al. (2016) Widespread transmission of independent cancer lineages within multiple bivalve species. Nature 534:705-709.

Munkvold GP, Hellmich RL and Rice LG, (1999) Comparison of fumonisin concentrations in kernels of transgenic Bt maizehybrids and non-transgenic hybrids. Plant Dis 83: 130 - 138.

Muenst, S., Läubli, H., Soysal, S. D., Zippelius, A., Tzankov, A., \& Hoeller, S. (2016). The immune system and cancer evasion strategies: therapeutic concepts. Journal of Internal Medicine, 279(6), 541-562.

Murchison EP, Wedge DC, Alexandrov LB et al (2014) Transmissible dog cancer genome reveals the origin and history of an ancient cell lineage. Science 343:437-440.

NCI (National Cancer Institute). 2003. Lag Time.

http://press2.nci.nih.gov/sciencebehind/cancer/cancer31.htm

830 Nordlee, J. A., Taylor, S. L., Townsend, J. A., Thomas, L. A., \& Bush, R. K. (1996). Identification of a Brazil-nut allergen in transgenic soybeans. New England Journal of Medicine, 334(11), 688-692.

O'Neill, I. D. (2010). Tasmanian devil facial tumor disease: insights into reduced tumor surveillance from an unusual malignancy. International Journal of Cancer, 127(7), 1637-1642.

Pace, J. K., Gilbert, C., Clark, M. S., \& Feschotte, C. (2008). Repeated horizontal transfer of a DNA transposon in mammals and other tetrapods. Proceedings of the National Academy of Sciences, 105(44), 17023-17028.

Pacheco, J. M., Santos, F. C., \& Dingli, D. (2014). The ecology of cancer from an evolutionary game theory perspective. Interface Focus, 4(4), 20140019.

Panchin, A. Y., Aleoshin, V. V., \& Panchin, Y. V. (2019). From tumors to species: a SCANDAL 
Peto, R., Darby, S., Deo, H., Silcocks, P., Whitley, E., \& Doll, R. (2000). Smoking, smoking cessation, and lung cancer in the UK since 1950: combination of national statistics with two case-control studies. Bmj, 321(7257), 323-329.

Prentice, C. 2018. USDA outlines first-ever rule for GMO labeling, sees implementation in 2020. labeling-sees-implementation-in-2020-idUSKCN1OJ2TF

Roff, R. J. (2009). No alternative? The politics and history of non-GMO certification. Agriculture and Human Values, 26(4), 351.

Romeis, J., McLean, M. A., \& Shelton, A. M. (2013). When bad science makes good headlines: Bt maize and regulatory bans. Nature Biotechnology, 31(5), 386.

Schartl, M. (2008). Evolution of Xmrk: an oncogene, but also a speciation gene? Bioessays, 30(9), 822832.

Séralini, G.-E., Clair, E., Mesnage, R., Gress, S., Defarge, N., Malatesta, M., ... de Vendômois, J. S. (2012). Long term toxicity of a Roundup herbicide and a Roundup-tolerant genetically modified maize. Food and Chemical Toxicology, 50, 4221-4231. doi:10.1016/j.fct.2012.08.005

Siegel, R. L., Miller, K. D., \& Jemal, A. (2016). Cancer statistics, 2016. CA: A Cancer Journal for Clinicians, 66(1), 7-30.

Singh, M. B., \& Bhalla, P. L. (2008). Genetic engineering for removing food allergens from plants. Trends in Plant Science, 13(6), 257-260.

860 Snell, C., Bernheim, A., Bergé, J. B., Kuntz, M., Pascal, G., Paris, A., \& Ricroch, A. E. (2012). Assessment of the health impact of GM plant diets in long-term and multigenerational animal feeding trials: a literature review. Food and Chemical Toxicology, 50(3-4), 1134-1148. 
Stone, G. D. (2010). The anthropology of genetically modified crops. Annual Review of Anthropology, 39, 381-400.

865 Strakova, A., \& Murchison, E. P. (2015). The cancer which survived: insights from the genome of an 11,000 year-old cancer. Current Opinion in Genetics \& Development, 30, 49-55.

Soucy, S. M., Huang, J., \& Gogarten, J. P. (2015). Horizontal gene transfer: building the web of life. Nature Reviews Genetics, 16(8), 472.

Tian, X., Azpurua, J., Hine, C., Vaidya, A., Myakishev-Rempel, M., Ablaeva, J., ... \& Seluanov, A. (2013). High-molecular-mass hyaluronan mediates the cancer resistance of the naked mole rat. Nature, 499(7458), 346.

Toole, B. P. (2004). Hyaluronan: from extracellular glue to pericellular cue. Nature Reviews Cancer, 4(7), 528.

Tyson, J. J., Chen, K., \& Novak, B. (2001). Network dynamics and cell physiology. Nature Reviews Molecular Cell Biology, 2(12), 908.

Vitale, I., Sistigu, A., Manic, G., Rudqvist, N. P., Trajanoski, Z., \& Galluzzi, L. (2019). Mutational and antigenic landscape in tumor progression and cancer immunotherapy. Trends in Cell Biology 29(5): 396-416.

West, S. A., Griffin, A. S., \& Gardner, A. (2007). Evolutionary explanations for cooperation. Current Biology, 17(16), R661-R672.

Woods, G. M., Howson, L. J., Brown, G. K., Tovar, C., Kreiss, A., Corcoran, L. M., \& Lyons, A. B. (2015). Immunology of a transmissible cancer spreading among Tasmanian devils. The Journal of Immunology, 195(1), 23-29.

\section{Supplemental Methods}


Two batches of Drosophila food are made simultaneously, one as a control and one with a food additive to be tested, according to the following recipe.

Ingredients:

Starting water $3,125 \mathrm{~mL}$

890 Hydrating water $625 \mathrm{~mL}$

(Organic, non-GMO) Corn flour 272.5g

Yeast 47.5g

Sucrose $80 \mathrm{~g}$

Dextrose $157.5 \mathrm{~g}$

$895 \quad$ Agar 37.5g

Nipagen 50 mL (5g tegosept/50 mL 95\% ethanol)

Instructions:

Fill a large pot with the starting water and put on full heat.

Fill the smaller pot with hydrating water.

900 Add sucrose and dextrose to the starting water and stir.

Add agar to the starting water when simmering and stir.

Put the corn flour and yeast in the hydrating water and stir.

Once the sugar/agar mix has turned golden and there are no longer clumps, add the corn flour/yeast mixture and stir.

905 Autoclave on liquid setting, sterilization time $20 \mathrm{~min}$.

Keeping the food warm on the hot plate add the food additive or same volume/weight water for the control and stir.

Pour the food while liquid into individual vials.

Add nipagen to the surface of the food after 10 minutes when it has cooled significantly (to prevent 
bioRxiv preprint doi: https://doi.org/10.1101/2021.01.07.425757; this version posted January 8, 2021. The copyright holder for this preprint (which was not certified by peer review) is the author/funder. All rights reserved. No reuse allowed without permission.

910 mold on the food surface). 